\title{
Maltese exceptionalism in the populist trend
}

\author{
Caroline Leusch ${ }^{1}$
}

\begin{abstract}
Malta, as the smallest state of the European Union (EU), has often been neglected when it comes to examining the surge of populism all over the Union. This is due to the fact, that Malta is believed to not have a problem with populism. Nevertheless, some populist parties exist, which are however unable to gain ground during elections and are not expected to enter the national parliament or government any time soon. This study examines why, so far, Malta was able to escape the populist trend and thus, represent an exceptional phenomenon. In order to do so, various factors are taken into account ranging from economy and culture to politics and geology. Populism in this research is examined as arising from severe conditions or i.e. a crisis, to take into account a widely-accepted scholarly argument. The main argument of the study holds that despite experiencing several crises, which could have led to populism, the country was able to withstand populism due to several factors.
\end{abstract}

\section{Introduction}

With some exceptions, populism has only been a marginal phenomenon in the history of Europe and especially since World War II. However, this development is currently taking a rapid turn as during the last decade, elections all over Europe have confirmed the rise of populism (Poli, 2016). Especially in the UK, Italy, the Netherlands, Germany, Greece and Finland, populist radical right parties are on the rise and intensively promote anti-European, anti-multiculturalism and anti-establishment feelings. Whilst numerous studies have confirmed the rise of populism in several European countries (Mammone, Godin \& Jenkins, 2012; Eatwell \& Goodwin, 2018; Mudde \& Kaltwasser, 2012; 2017; Van der Brug, Fennema \& Tillie, 2000), there are some exceptions to this trend. Malta so far appears to have escaped the claws of populism with no populist party being in government, opposition, parliament or European Parliament representative. It is often argued that Malta does not show any signs of the populist trend but there are nevertheless some populist parties that participate in general elections, even if they cannot record any electoral successes. Therefore, this paper seeks to examine why Malta was able to escape the populist surge that is currently prevailing in Europe?

However, due to this almost non-existence of populism, there have been barely any studies to examine the bit of existing populism in Malta or the reasons of why Malta was able to resist its spread, with some exceptions that are however, not up-to-date anymore (Falzon \& Micallef, 2008). As there has been no academic research specifically dedicated to the different reasons underlying the exceptionalism of Malta when it comes to escaping populism, for the sake of this research a wide array of literature is examined to include insights from different perspectives, that are indirectly linked to populism. Previously, Malta has often been the subject of interest, especially when it comes to politics due to its special two-party system or economics due to its resistance towards the Global Financial crisis (Cini,

${ }^{1}$ Caroline Leusch received a bachelor degree in European Studies at Maastricht University in 2019. At the moment she takes a Master in Political Science, European and International Governance at Vrije Universiteit Brussels. Contact: caroline.leusch@gmail.com 
2002; Pace, 2017; Azzopardi, 2009). However, as there is barely any populism, the movement of nationalism, has been discussed more, also in the context of increasing immigration and anti-migratory sentiments but also in terms of identity (Baldacchino, 2002; 2009; Mitchell, 2003; Pace, M. 2006). This serves as a basis for this research, as the thin-centered ideology of populism is often aligned with a thicker ideology such as nationalism (Mudde, 2007). This paper, moreover, focuses on the right-wing branch of populism and excludes the left-wing ideology from its research, as there no left-wing populist parties exist in Malta.

In order to fill this literary gap, a combination of several theories will be applied to account for the various aspects of Maltese populism. Therefore, the research is divided into three sub questions, which allow the study to provide context and background on the Maltese case. In order to study the Maltese exceptionalism in terms of populism, the paper examines populism in the context of extreme conditions or crisis, an argument put forward by several authors, who claim that populism mostly arises from a severe crisis (Scheuch \& Klingemann, 1967; Mudde, 2010). In order to apply this argument to the Maltese case, several episodes of migration as well as the continuing quest to define a Maltese identity are examined as crises. However, as there is no successful populism to be found in Malta, it is argued that either the crises were not severe enough in the context of the argument or that the Maltese case constitutes an exception to the theory. In order to examine why populism was unable to gain grounds within the Maltese electorate, an analysis based on economic, cultural, geological, political and economic factors is applied to differentiate the Maltese development from the development in most of the other European countries.

The paper is structured as follows: firstly, the theories and main arguments are outlined, on which the analysis is based. Secondly, two crises are examined in the context of populism to conclude, that there is actually potential for populism in Malta. These crises consist of an internal identity crisis and an external migration crisis. Thirdly, a background on the existing populist parties in Malta is provided and they are classified into two different strands, according to the theoretical framework. Lastly, the analysis examines 5 factors that prevented the rise of populism, based on the 4D framework set out by Eatwell and Goodwin (2018). Lastly, the conclusion will summarize the key findings and answer the research question accordingly.

\section{Theoretical Framework}

\subsection{Populism, the normal pathology thesis and pathological normalcy}

Before examining the relevant theoretical arguments, it is crucial to define the notion of populism first, as it constitutes the main concept of this research. Despite being widely applied, the concept of 'populism' is also widely contested (Roberts, 2006; Barr, 2009). To simplify this divide in existing literature, this paper applies the definition offered by Mudde, who is simultaneously the main theorist that is referred to in this study. Mudde defines populism "as a thin-centered ideology that considers society to be ultimately separated into two homogeneous and antagonistic groups, 'the pure people' versus 'the corrupt elite', and which argues that politics should be an expression of the volonté générale, i.e. the general will of the people" (Mudde, 2007, p.23). The dominant positions in academic literature concerning populism are based on the normal pathology thesis, which holds that radical and extremist ideas are fundamentally opposed to the ideas of liberal democracy (Mudde, 2010, p.1168). Scheuch and Klingemann (1967), proponents of the theory, argue that the rise of the far right is considered a

\footnotetext{
$2 \mid$\begin{tabular}{l|l} 
Marble \\
Research \\
Papers
\end{tabular}
} 
'pathology of modern society', comparable to fascism or a psychological disorder. Thus, populist values constitute something that lays in stark contrast to the values of liberal democracies, but nevertheless a small potential for populism exists in every society. This potential then is triggered by extreme conditions and eventually results in structurally determined pathologies (Mudde, 2010, pp. 1170-1171). Mudde (2010) proposes a shift away from demand-side focused explanations on the rise of populism and provides a metatheoretical analysis when rejecting most of the arguments of the normal pathology thesis and empirically contesting them. He argues that populist values are different from democratic ones but that these "anti-establishment sentiments are also closely connected to broadly shared beliefs in western societies" (Mudde, 2010, p.1175). When examining surveys concerning nativism, Euroscepticism, authoritarianism and anti-immigration, it becomes clear that such populist values are shared by a large proportion of European citizens and thus, have more than only a small potential to spread. Mudde concludes that the populist radical populist beliefs, hence, constitute a mere radicalization of mainstream views and thus a pathological normalcy them (2010, p.1178). The pathological normalcy thus acknowledges populist ideologies as part of democracies, whereas the normal pathology thesis argues that they are fundamentally opposed to liberal values, and thus, only a small potential for them to spread should exist.

Hence, even if there is no consensus on whether populism is part of the development of liberal democracies or if it is an anomaly to it, the origins of how populist values are triggered, appear to be simpler to determine. Despite counterproving the normal pathology thesis, Mudde does not reject the argument that populist attitudes often result from extreme crisis-alike conditions. Therefore, it can be said that there is general consensus on this specific argument both from demand- and supply-side explanations as it is incorporated in both the normal pathology thesis and the pathological normalcy theory. The biggest counter-argument offered to both the pathological normalcy thesis and the normal pathology thesis is that populism and crisis are both too vague concepts and can hence not be defined in relation to each other (Knight, 1998, pp.227-228). Knight (1998) argues, that populism can also exist in normal and not extreme situations and there is at best a loose association between both concepts. Additionally, it is argued that there is always a crisis going on as crises constitute an inevitable element of modern democracies and nevertheless, populism is not always triggered (Poli, 2016, pp.42-43). Poli acknowledges the struggle to define 'populism' and 'crisis' but concludes that this conceptual difficulty does not make their link weaker because history has shown that the relation between populism and crisis cannot be neglected (2016, pp.42-43). Others agree that some degree of crisis is a necessary precondition for the rise of populism as it arises in reaction to change and challenge (Laclau 2005, p. 177; Taggart, 2004, p. 275; 2002, p. 69). Moreover, a crisis is crucial in framing populist parties' policies "to inject an urgency and an importance to their message" (Taggart, 2004, p. 275).

Hence, despite having some opponents, there are numerous supporters of the argument, wherefore it will provide a basis for this study to examine the virtual non-existence of populism in Malta. A crisis is thus both an internal and external element of populism as populism usually emerges from crisis and simultaneously takes advantage of it to gain electoral success, hence both 'being fed by and drinking from' crisis. 


\subsection{The four D's and the underlying reasons for populism}

Goodwin and Eatwell (2018) are two of the leading scholars when it comes to analyzing populism and its causes on a short and long term. In their work National Populism, they identified four key drivers that stimulate the rise of populism by scooping out its potential in different domains. Their factors can be applied to wide array of domains, but for the sake of this paper, five domains have been selected within which the four D's, as they call them, are examined. The four D's will now be outlined.

Firstly, a distrust in the leading politicians and institutions of our elitist liberal democracies leads to a bigger voter/politician gap and often citizens feel like they have no voice in national affairs anymore. This can not only be observed on a local level with mainstream parties but also in institutions such as the EU or the US Congress. Secondly, the feeling of a national identity and established ways of living being destructed e.g. through the arrival of hundreds of migrants that are feared to introduce cultural changes due to an increased ethnic diversity. Thirdly, current economics are transforming which results in a sense of relative deprivation due to rising inequalities in e.g. income or wealth, wherefore citizens lose faith in a better future. People feel like they are relatively losing out compared to others, especially when it comes to issues such as immigration and identity. Lastly, the gap and bonds between mainstream parties and their electorate is widening and people are de-aligning from their initial political views and mainstream parties. Thus, citizens become less loyal to mainstream values and turn to more radical views. Together, these four D's provide the "pool of potential" by contesting existing studies on populism by combining insights form both economics and culture instead of focusing on either one of them (Eatwell \& Goodwin, 2018, p. xxiv).

\section{Methodology}

In order to account for the exceptional role Malta plays in the wider European trend of populism, it is crucial to take into account a wide array of factors and levels. As there is not one single theory that explains the Maltese controversial development thoroughly whilst taking into account how populism emerges but also how it is prevented, a multitude of theories and arguments is needed. Because the Maltese case is conflictual and an exception, as the Maltese experienced crises which in turn did not lead to a success of populism, there is no theory to explain both developments. Accordingly, this paper employs a multi-theoretical approach by combining the following theories to gain an interdisciplinary but quantitative understanding of the Maltese phenomenon. Therefore, the argument proposed by both normal pathology and pathological normalcy theorists concerning the populism-crisis relation, provides the analytical basis to examine populism in terms of crises. These theories are then applied more generally to provide a historical background on the few populist parties in Malta and how the crises had an impact on them. Lastly, the four D framework provides the empirical factors to explain the reasons Malta was able to escape populism.

Despite being subjected to severe criticism due to difficulties concerning its definition, for the sake of this research the concept "crisis" must be examined. Mudde also acknowledges skepticism concerning this argument, as he agrees that it is difficult to define the concept of 'crisis' (2007, p.205). Despite being a rather vague concept, it can still be defined loosely. The idea of a crisis in that sense is, that society is transforming fundamentally and rapidly, which leads to a division between the winners and losers of such a change (Mudde, 2010, p.1172). The 'losers' will vote for more radical and populist parties out of anger and to make their voice heard. Thus, under massive societal changes, "the losers of

\footnotetext{
4 \begin{tabular}{l|l} 
Marble \\
Research \\
Papers
\end{tabular}
} 
modernization will vote for populist radical right parties" (Mudde, 2010, p.1172). Known examples for such a deep crisis are globalization, the risk society, the post-Fordist economy, the postindustrial society etc. (Mudde, 2010, p.1172). The ongoing Euroscepticism crisis can also be seen as a trigger for populist parties as Eurosceptics often blame the EU or i.e. the corrupt elite for all bad happening (Poli, 2016, p. 46). But what about a more internal crisis such as a lacking identity or an external crisis that massively influenced population flows all across the EU? This argument concerning the correlation of crisis and populism, thus provides the basis to examine why there should be potential for populism in Malta, as its citizens witnessed two specifically crucial crisis in the last 15 years. The first crisis concerns the problems the Maltese encountered to establish their own identity, which was problematic due to several reasons. The second crisis consists of several phases, which will be examined but the focus of this paper only lays on the most current phases of migration.

As mentioned earlier, there are several parties in Malta that promote populist ideologies, wherefore it is necessary for this analysis to provide a background on them. Thus, after establishing that there were two crises, that could have led to increasing populism, the second sub question is examined, concerning the impact these crises had on the development of Maltese populist parties. In order to do so, the existing populist parties in Malta are classified into two distinct waves and explained within either the normal pathology or pathological normalcy framework. Both frameworks were examined in the theoretical framework.

The last section then examines the last sub question, namely what factors prevented the rise of populism in Malta? In order to understand why the theory of crisis fueling populist sentiments does not apply to Malta, it is crucial to examine the factors that elsewhere supported the rise of populism. Therefore, two of the leading scholars concerning the analysis and examination of the populist trend, concluded that populism is stimulated by four factors (Eatwell \& Goodwin, 2018, pp.xxi-xxiii). These four D's consist of distrust in politicians, the destruction of identity, relative deprivation due to rising inequalities and lastly, the de-aligning from mainstream parties and values and the lack of loyalty for these. In order to operationalize the research, these 4 D's are examined from different perspectives to account for the interdisciplinary nature of populism. These perspectives include economy, culture in terms of religion, national and European politics as well as geography.

The data and sources used for this study consist of primary and secondary sources. Primary sources are retrieved from the European institution's websites, wherefore their reliability and authenticity should be ensured. Secondary sources consist of academic literature but also journal articles from well-known Maltese magazines, which are supposed to provide an insider's point of view on the phenomenon. As these might be biased, they are contrasted with the general findings of academic scholars. These have been published by well-known publishers or reliable university presses, which ensures their reliability.

\section{Analysis}

\subsection{Why should populism be successful in Malta?}

For the sake of this argument, this research builds on two different crises in which context the argument that a crisis is crucial in developing the quest for populism, will be examined. Firstly, the identity crisis will reveal the deep split within the Maltese society. Secondly, immigration problems possibly further trigger the rise of populist parties as developments in other European countries proved that rising 
numbers of migrants stimulated a higher sympathy for populist and radical parties. However, this trend cannot be traced back in Malta: populist parties do exist, but they have such low numbers of followers and perform badly during election time that it is argued that Malta does not have a populism problem. It will be examined to what extent these crises fit the theoretical framework and thus should have been factors in promoting the rise of populism but in contrast didn't do so.

\subsubsection{The identity crisis}

The Maltese identity crisis has partly been examined in terms of nationalism (Baldacchino, 2002), which is also crucial for this analysis as nationalism can be seen as a thick ideology, to which a thin ideology such as populism aligns (Mudde, 2007). Therefore, nationalism can sometimes be seen as some sort of pre-state to populism. In order to examine the quest to form a Maltese identity, several factors will be examined as "elements of identity include ethnicity, language, religion, cultural values and customs, a distinct historical self-view and a sense of territorial bonding" (Baldacchino, 2002, p.194). The Maltese population is a rather homogenous ethnicity, of which barely $2 \%$ of Maltese citizens have another nationality than Maltese (Baldacchino, 2002, p.194). This is somewhat surprising as until the Middle ages, Malta was formed through several different immigration waves from differing origins. The closest Malta comes to a national identity is through its connection with the Catholic church, with which most citizens identify. This religious affiliation also determines most of Maltese cultural values, aligns the population and constitutes a form to express cultural nationalism (Baldacchino, 2009, p.161; Abela, 2006, p.23-24). However, additionally to the church's influence comes the influence of political affiliations, which also determine culture and customs fundamentally. Depending on the party affiliation, one celebrates different national days in Malta. For example, the nationalists determined September 21st as national day, as in 1964 this day was declared Maltese Independence Day. In contrast, the labor party promotes Freedom Day March 31st as the only national day as this marks the date when the last British troops left the country in 1979 (Pace, M., 2006, p.111). Therefore, party affiliation constitutes a dividing factor in Maltese society and poses a hindrance to the creation of a homogenous external national identity .

Additionally, after joining the EU, it was highly debated what Maltese iconic national symbol should be printed onto the euro coins, as there was no known national symbol, which further illustrates the identity struggle of the Maltese (Baldacchino, 2002). This might also have historical reasons: the Maltese only very late rose against their British oppressors, when these decided to back out of the country. Thus, the Maltese never fought for their land to gain their independence back and thus did not have to forge a coherent nationality (Baldacchino, 2009, p.151). Additionally, even after their independence, they had to rely massively on other countries', especially Great Britain's, military presence, and thus were reluctant to form a national identity or form some sort of "self" with other nations involved. Malta is a young country and so are its constructions of identity (Cini, 2000, p.270). Cini (2000) classifies the Maltese quest for identity into two phases: the first geological expression of identity focused on defining the country as 'Mediterranean' rather than European. This acknowledged its unique position as well as important relations with the European countries but also their North-African neighbors. The second construction of identity views the country as a mostly European state, even prior to its EU accession because of their shared characteristics with other European countries (Cini, 2000, p.171-172). This construction is based on their Christian democratic values and the 'Mediterranean identity' is only of secondary importance. The first form of identity was mostly advocated by the Maltese 
Labor Party whereas the more European-oriented approach was pushed for by the Nationalist party, which also emphasized the importance of EU-membership later.

Another source of friction in forming a national identity concerns language. Nowadays, the official languages in Malta are English and the Maltese language. Nevertheless, despite the rising prominence of English, Maltese is still considered the mother tongue of most citizens, wherefore the language requirement of identity seems to be fulfilled as language appears to not constitute a dividing character of Maltese society. However, this has not always been the case and this conflict may seem resolved on the surface but most likely still exists internally. Maltese identity has been highly debated since the 19th and especially 20th century, as the country had close ties with both Italy and Great Britain (Cini, 2000, p.271). From these cleavages arose Maltese party politics: the pro-Italian movement was politicized through the creation of the Nationalist Party whereas the pro-British sentiments developed into the Malta Labor Party (Mitchell, 2003, p.381). This fragmentation led to a competition over the official language in the 19th century when two visions for the future of Malta arose. The first one included closer ties to the UK and thus adopting the British language and the other one promoted close relations to Italy and imposing the Italian language (Cini, 2002, p. 18). With both countries, Malta had strong historical links due to colonialism and the pre-modern era. Nowadays however, this conflict seems to be very diplomatically resolved: Maltese is the primary and mother tongue of the Maltese with English officially and Italian unofficially as second languages. This conflict concerning the national language constitutes however, another sign for the fragmentation of the society and highlights the problem of forming a national identity. Additionally, Cassar concluded that the language factor in defining a national identity is a problematic one as can be also seen in other European countries such as Belgium or Luxembourg (2001, p.270). However, during their accession talks to the EU, it was important for the Maltese, as a sign of identity, to have the Maltese language acknowledged as an official language of the EU. The EU agreed and simultaneously recognized the country's catholic identity in a protocol, including sovereignty on the right of abortions (Pace, R. 2006, p.42).

The foregoing analysis has shown that the Maltese society is homogenous in ethnicity, territory, religion and history but is divided and shaped by the influence of the two main parties and earlier especially by their pro-British and pro-Italian policies. The latest cleavage that was uttered through the parties was around the turn of the millennial, when the Nationalists expressed a pro-European attitude and Labor a Eurosceptic one (Harwood, 2014, pp.195-196). Since its accession to the EU, a more secular and national Maltese character has evolved, partly contributing to forming its identity (Baldacchino, 2009, p.161). Despite religion being an important source of identity, the ongoing immigration in the country may suggest that the Maltese identity also somewhat evolves as a response to increasing numbers of immigrants, which therefore constitute a 'significant other', being different from the Maltese nation.

\subsubsection{The migration crisis}

Ever since the beginning of the new century, Malta has experienced several immigration phases, especially from its southern neighbor, particularly the sub-Saharan countries. The first wave of illegal migration started in 2002. After initial sympathy sentiments, the peak of the crisis was reached in 2004 and sympathy had shifted to make place for anger and hatred towards the migrants (Falzon \& Micallef, 2008, p. 394). Ever since 2002, a mandatory detention policy was implemented by the government to keep count of immigrants and frame the situation as a migration crisis, as due to its small population, 
increasing numbers had a significant impact on the country (Mainwaring, 2012, p. 687). However, this was not necessarily because of anti-immigration attitudes of the main parties but more to illustrate the complexity of the crisis and maybe enforce EU involvement.

The first 'real' crisis resulted from the Arab Spring revolts, which confirmed the close link Malta still held with the Northern African countries. This crisis had a significant impact on population numbers and immigration sentiments. During the Arab Spring, thus between 2008 and 2012, Malta received, on European average, the highest number of asylum seekers compared to its national population. Comparatively, one migrant coming to Malta equals thousands of them coming to bigger European states due to its small size and population. Malta was considered a transit country for many migrants on their way to Europe but due to its attractiveness in terms of economy, nevertheless, had a considerable amount of asylum seekers. However, the Maltese population was not pleased about the situation and anger mounted over rising illegal immigration (Falzon \& Micallef, 2008; Mainwaring, 2012). They made the EU responsible for not helping enough, blamed Libya for not preventing the migrants from leaving and held the arriving migrants liable themselves. However, again, as in the 2004 crisis, there was a change of perception towards migrants later on: as there was no political solution in sight, sentiments shifted to some sort of resignation towards the problem (Falzon \& Micallef, 2008, pp. 397-398). In contrast however, the government disagreed and concluded an agreement with Italy to "push back" arriving migrants in 2010 and therefore decrease arrivals in Malta drastically (Mainwaring, 2012, p. 689). Conclusively, the 2010 election was not affected by populist attitudes as migration numbers decreased drastically: in fact, Norman Lowell (leader of Imperium Europa, a populist anti-immigration party) campaigned as a "last call of resistance" against the takeover of the country by immigrants but was only able to poll a mere 84 votes (Falzon \& Micallef, 2008, p. 398). The push back policy, however, was abandoned in 2011 due to the political conflict in Libya and Malta was forced by the EU to accept migrants. This increasing immigration then again fueled anti-immigration rhetoric and policies of the existing Maltese populist parties, but even in the next European parliamentary elections 2014, these parties could succeed in actually contesting the established main parties as will be elaborated on in the next section. However, the votes for populist party leader Norman Lowell (Imperium Europe) doubled to 7.000 in 2014 compared to the 2009 European election and rose up to 8.3000 in 2019, thereby obtaining $3.2 \%$ of all Maltese votes (Vella, 2019).

However, the perception towards migrants radicalized again in the wake of the 2015 crisis. Malta was then known for its harsh detention policies, wherefore it became a less attractive country for migrants, but it also showed the radical stance towards migrants (Mainwaring, 2012). However due to civil right violations, the country had to abandon this policy in late 2015 (Global Detention Project, 2017). Therefore, during 2015, Malta only accommodated comparatively few migrants, as most were taken to Italy or refused to land in Malta due the prospect of a compulsory detention policy and human rights violations. Nevertheless, when the crisis worsened between late 2015 and 2018, Malta still accommodated the second-highest number of refugees per capita (18.2 per 1,000 people) and maintained the fourth-highest proportion of positive decisions on asylum application (68.7 percent) in the EU (Mainwaring, 2019). In order to check irregular immigration, create a buffer zone and establish a presence beyond its borders, such as at sea, the EU southern countries seek to externalize their border and thus create a barrier for illegal migrants to arrive (CEAR-EUSKADI, n.d., p.10). Despite attempts to externalize its borders and cooperate with Libya closely to prevent further migrant boats from arriving, Malta was bound to international and European law and thus obligated to accommodate migrants 
(Mainwaring, 2019). However, despite rising levels of migration, populist parties in Malta still could not succeed in the 2017 local elections when the newly formed Moviment Patrijotti Maltijn and the Alleanza Bidla firstly contested local elections. Nevertheless, $61 \%$ of Maltese see immigration as the greatest concern and biggest problem that the EU currently faces, which is $20 \%$ higher than European average (Eurobarometer, 2018). Additionally, 50\% of Maltese see immigration also as the biggest concern on a national level, being followed by $36 \%$ in Germany (Eurobarometer, 2018). Hence, immigration poses a significant problem to the Maltese.

After the 2019 European elections, Imperium Europe's leader Lowell's far-right party, thus became the third biggest party in Malta even overtook the Greens, which were the third strongest party until 2019 (Vella, 2019). Nevertheless, despite rising arrivals of immigrants, populist parties were still not able to actually challenge the two mainstream parties, whose votes together take $90 \%$ of the electorate, wherefore even an increase to $3 \%$ of the populist party does not change their position. The result underlines that also in Malta, populist sentiments exist and appear to be (very slowly) increasing. This, however, seems to only be true for European elections, as in local ones, the populist parties don't even get $0.5 \%$ of all votes. Therefore, it can be argued that both migration crises did not trigger a rise in populism as despite some anti-immigration sentiments, Maltese citizens did not allow populist parties to gain ground in their society.

Conclusively, it can be said that the crises were either not severe enough to trigger populism or Malta can be seen as an exceptional case. The identity crisis may be subject to the argument that it was not severe enough as it 'only' constituted an internal conflict and did not include any "extreme conditions". Society was not rapidly transforming and there were no 'winners' or 'losers' as required by Mudde's idea of 'crisis' (Mudde, 2010, p.1172). However, this paper argues that both the 2015 migration crisis but in particular the Arab Spring crisis were severe enough to count as a crisis. They led to extreme conditions such as an increased hatred towards migrants, dividing society over what to do, leading to a rapid transformation and introducing a perception of winners vs losers among those more or less affected by rising migration numbers in terms of employment etc. Thus, when looking at the argument from the context of immigration, Malta constitutes an exception to the theory, especially when examining how the migration crisis in 2015 fueled the rise and sympathy towards other European populist parties.

\subsection{How did the crises impact populist parties' success in Malta?}

\subsubsection{Background on populism in Malta}

In general, the populist radical right in Malta can be described as heterogenous and formless, (Falzon \& Micallef, 2008, p.394). It is possible to establish two separate waves of populism in Malta. The first one, starting in 2000 came to an end after the elections of 2008 and 2010 as the parties could not establish a wider voting ground. The second wave of populist parties encountered the consequences of the Arab Spring and the crisis of 2015 as well as the more mid-term consequences of the global financial crisis. This wave of populist parties continues to the date of writing.

The first wave of populism entailed parties such as Imperium Europa and the National Action, but also pressure groups such as Vivamalta and the National Republican Alliance. These parties were established rather early but most of them could not survive long, with the exception of Imperium Europe. Imperium Europa in essence advocates the individual political standpoint of Norman Lowell and advocates the ethnic cleansing of Europe, promotes white supremacy and cosmotheism, spreads anti- 
Semitism sentiments and is very racist in its anti-immigration rhetoric (Falzon \& Micallef, 2008, p.395). Lowell was the most prominent Maltese populist but later was convicted because of him inciting to racial hatred and was among the first Maltese to be handed a jail sentence (later reduced to 15 months of probation) for doing so (Falzon \&Micallef, 2008, p.395). Another official populist party was the National Action, a nationalist, conservative and anti-immigration party, which was transformed into a pressure group after failing at the elections of 2008 and 2010 (Falzon \& Micallef, 2008, p. 396). The party was said to be distinctly linked to inter-war fascism. The similar National Republican alliance was established in 2005 to promote conservative and anti-immigration values but was dissolved only two years later (Falzon \& Micallef, 2008, p. 396). Vivamalta is neither a pressure group nor a political party, but an online forum in which supporters can express their sentiments freely. The website and its adherents are partly devoted to fascism and in 2008 promoted a political candidate for the elections, who failed miserably (Falzon \& Micallef, 2008, p. 395).

This first wave of Maltese populist parties can be classified within the framework of the normal pathology thesis. These parties hold and represent values that lay in contrast to the democratic values of the nation. Their existence can only be explained outside the 'normal' as they can be described as an anomaly of democracy (Mudde, 2010, pp.1171-1172). Especially the anticipated link to fascism by several of the parties confirms this argument as populist parties were often studied from the perspective of fascism. It is then often assumed that this kind of populism is more a "remnant of a distant past, not as a consequence of contemporary developments" and thus outside of the normal democracy framework (Mudde, 2010, p.1171). However, this argument was mostly made in the intermediate inter-war period where the link to Nazism and fascism was closer than in the new century. Nevertheless, because before, Malta had no populist parties until then, the argument can still hold if Malta experienced a somewhat shifted evolution, partly due to their long colonization.

Except for Imperium Europe, all populist expressions of the first wave have dissolved, which indicates again that the first migration crisis of 2002-2006 did not have a significant impact in encouraging populism to rise. However, the Arab spring and its consequences for Malta as well as the recent migration crisis led to an increase in populist right wing parties in Malta, which had barely seen any right-wing political activities after the disbandment of most of the above-named parties. The two new populist parties Alleanza Bidla Party and Moviment Patrijotti Maltin attempted to fill in the cracks from the mainstream parties, where voters seemed to be concerned about 'nativist' concerns like identity, culture and the effects of migration (Pace 2017). They propose an alternative to the Labor and Nationalist party, one of which was always the incumbent government since Malta's independence. Alleanza Bidla has established a clear agenda based on values from euro-skepticism and conservatism with the intention to preserve traditional Maltese Christian values and abandon the neo-liberal values of the EU (Diacono, 2017). In a nationalist sense, they want to refocus on Maltese identity, culture and art. The party was founded in 2013. Moviment Patrijotti Maltin is a far-right wing, nationalist, antiimmigration party, which opposes the presence of Islam (Kurt, 2016). It was founded as an antiestablishment party in 2016. The party is known for blaming rising immigration for the problems faced by the Maltese society, such as elevated rent and property prices to traffic jams (Diacono, 2017).

The second wave of Maltese populism can be explained in terms of the pathological normalcy thesis. Their views of euro-skepticism and anti-immigration exist within the framework of democracy, in contrast to the fascist views laying outside of its boundaries. Euroscepticism is part of democracy, as it is normal to query why it is necessary to delegate sovereignty to Brussels. Anti-immigration feelings are 
also somewhat understandable if a country is facing large influxes of foreigners, in that citizens might feel threatened. Also, the quest for nationalism and thus an identity is normal in democracies and cannot be associated with the extreme right. Sentiments that are part of the pathological normalcy thesis, are more broadly accepted than normal pathology feelings such as extremism, which attract a much smaller electorate.

As was seen in the foregoing explanations, there are several parties that represent populist beliefs in Malta. However, none of them can claim to be successful, despite their common practice to blame immigration and the EU for the problems faced by the Maltese. Lawrence Gonzi, former premier minister of Malta expressed in a recent interview that he is not at all concerned with populist parties in Malta as the electorate remains located between the center-right, center and center-left (Ziabari \& Gonzi, 2019). However, Malta needs to learn from the occurrences in other countries to prevent populism from rising in the future and not taking its immunity for granted (Ziabari \& Gonzi, 2019). Conclusively, the migration crises did not have a significant impact on the success of these parties. The influence of the identity crisis could not be examined as it constitutes an internal conflict that does not appear to shape political happenings in terms of populism significantly.

\subsection{What factors prevented the rise of populism in Malta?}

After examining that there was actually quite some potential for populism in Malta but also that populist parties did not succeed in elections, this study now turns to examine why the existing populist parties were unable to exploit this potential. This is due to several factors, that proved to be preventive to the development of populism. These factors were selected as in other countries, they partly proved to the influential factors in allowing populist ideologies to arise in the first place. Therefore, this study takes on a more reverse approach by selecting these factors and prove that they, in the Maltese case, proved to be of rather preventive nature. Despite not all being directly linked to populism these factors nevertheless played a crucial role in preventing the spread of populism.

The four $D$ framework provides the theoretical basis for the section. To recapitulate, the first $D$ concerns distrust in politicians. Secondly, identity destruction provides incentives for populism on a more cultural level. Thirdly, relative social and economic deprivation may stimulate anger and thus, increase the likelihood of voting for more radical parties. Lastly, a decline in loyalty towards mainstream values and parties leads to some form of de-aligning from the politicians and a bigger gap between electorate and elected. The foregoing analysis will examine to what degree the four D's identified by Goodwin and Eatwell (2018) were present or not within various perspectives and how they thus, not facilitated the development of populism.

\subsubsection{Economic stability}

One important factor that is often named in relation to the rise of populism is a badly performing economy, unemployment and related social problems, which lead to a dissatisfaction of the electorate (Eatwell \& Goodwin, 2018). However, in Malta, one of the factors that helped Malta to escape the populist wave is its stable economy with low unemployment and high levels of social capital, thanks to which the Maltese did not feel the ressentiment towards the government and abstained from voting for populist parties. According to the 2018 Eurobarometer, 95\% of Maltese stated that their national economy is in a good state, which is the best judgement among all European countries, followed by $91 \%$ 
in Luxembourg. Additionally, $94 \%$ see the job market and their financial situation as good (Times of Malta, 2018). Hence, it can be concluded that Malta is in a very good economic state.

Especially in the wake of the 2008 global financial crisis, it became clear that Malta as the smallest Member State of the EU was economically underestimated as they survived the 2008 crisis without much suffering. Despite not having own economic resources, a heavily dependent manufacturing sector and being dependent on fluctuating oil prices to be able to turn sea water into drinking water, Malta faced these economic challenges well and remained competitive (Ziabari \& Gonzi, 2019). Lawrence Gonzi, former prime minister of Malta from 2004 to 2013, associates this with the achievements made during his economic restructuring process before 2008, including "universal free health care, universal free education [...] as well as a relatively strong social safety net that supported the most vulnerable in our society", all of which were stabilizing factors during the 2008 crisis (Ziabari \& Gonzi, 2019). Additionally, Gonzi emphasizes two specific reasons as to why Malta was able to "sail through this crisis": the adoption of the euro and the Maltese flexibility due to its small size (Ziabari \& Gonzi, 2019). As a small island, Malta was able to be more flexible than other countries in coming up with new policies to circumvent the repercussions of the global financial crisis. During the first years of its membership, Malta went through a strict restructuring process to eventually adopt the euro by meeting requirements such as price stability, sustainable public finances, exchange rate stability and long-term interest rates (Ziabari \& Gonzi, 2019). To do so some sectors such as ship-building needed to be closed down or be privatized but losses were remade by creating new jobs in sectors such as aircraft maintenance, pharmaceuticals, care and financial services sectors (Ziabari \& Gonzi, 2019). Finally, on January 1, 2008, Malta introduced the euro. By fulfilling the convergence criteria, Malta's open economy was already in a good economic state prior the crisis and this economic stability helped it to overcome its repercussions. However, social problems persist in terms of the gender pay gap, which is rising the most compared to other European countries, gender employment differences, inequality in drug rehabilitation, a difficult housing situation with rising rents as well as unequal access to quality education (Times of Malta, 2019).

Thanks to its good economic state, the Maltese have no economic reason to turn against their government by voting for populist parties as they have not become dissatisfied with the established parties and trust in them has not been broken (Pace, 2017, p. 511). In contrast, because either the Nationalists or Labor have been the incumbent government for so long and this economic success can be attributed to their policies and the Maltese citizens will continue to vote for them as long as the country continues to enjoy economic stability. Consequently, trust in government in Malta is said to be among the highest within the EU. Trust in national government is currently at $63 \%$ and $59 \%$ for trust in parliament, whereas European average lay at 35\% for both in 2018, being worryingly low (Times of Malta, 2018). Hence, the first D concerning distrust in politicians is certainly not fulfilled and thus did not encourage populism to rise. However, the economic condition of the country is disturbed by rising social inequalities, especially when it comes to gender and housing. The third $D$, the sense of relative deprivation, could thus be partly fulfilled but appears to be somewhat set off or even undermined due to the good economic state of Malta which seems promising for a better future.

\subsubsection{Role of religion}

However, not only the economic state of the country at hand should be examined in order to explain the non-existence of populism. Besides the economic state of a country, its cultural condition is also crucial

\footnotetext{
12 Research Papers
} 
in supporting or preventing the rise of populist attitudes. In terms of cultural factors that potentially hinder or stimulate the rise of populism, the importance of religion cannot be underestimated.

All over the globe, radical right parties often describe themselves as the true defenders of Christian values, however, in most cases they do not seem to be able to attract a mass of religious voters (Montgomery \& Winter, 2015). This was especially observed in Greece, Croatia, Denmark and the Netherlands. However, it is unclear whether such parties have a genuine religious message or merely use this apparent promotion of Christian values to attract more voters (Montgomery \& Winter, 2015, p. 380). In Malta, especially the Alleanza Bidla party and Moviment Patrijotti Maltin leaders claim that their parties intend to defend conservative Christian values (Diacono, 2017). Alleanza Bidla even claims to be a Christian-democratic party. Both leaders argue that the traditional main parties abandon Christian values in favor of neoliberal ones whilst acting as "puppets of the EU" by promoting its values and abandoning the old Maltese values of "hard work, loyalty and respect" (Diacono, 2017). The populist parties want to reintroduce conservative Christian values such as anti-abortion, anti-divorce and antihomogenous-marriage as part of Christianity, which is crucial to the Maltese identity. However, despite Malta being a Catholic country with over $90 \%$ of citizens identifying as Catholics, these populist parties, apparently promoting Christian values were unable attract a significant number of Christian voters. This thus confirms previous studies that argue that populist radical right parties, despite claiming to be the defenders of Christianity, fail to attract religious voters in mostly Catholic countries (Montgomery \& Winter, 2015; Van der Brug et al. 2000). Other studies found that populist parties' voters are less religious than others (Lubbers et al., 2002; Norris, 2005). However, there have been no studies on the Maltese populist voters yet as to confirm or reject such an argument. In the study offered by Montgomery and Winter, they found that Christian religiosity correlates positively with nativism (offered by several populist parties) but not necessarily with populism, despite the two ideologies being closely related (2015, p. 399). This argues for the misuse of populist parties of Christian values as merely an instrument to attract Christian voters instead of spreading a religious message.

Especially when society is changing or undergoing major transformations, the previously held values might change and radicalize. As was seen during several migration episodes, not only in Malta, initial sentiments of pity and sympathy faded and were replaced by more harsh sentiments of anger as governments were unable to cope with such large unexpected influxes. However, this shift of sentiments is often due to biases against migrants despite studies proving their contribution to the local economy as they are an easy labor force, especially useful for "hire and fire" practices (Baldacchino, 2009, p. 158). The existing populist parties stepped in to promote policies to take care of the problem in their own way. This shift brought about more racist rhetoric in Maltese newspapers, television and politics in general (Falzon \& Micallef, 2008, pp. 397-398). Some politicians were even charged with the incitement of racial hatred and sent to prison, which gave a huge blow to the Maltese populist parties (Falzon \& Micallef, 2008, p. 398). Hence, it cannot be said that the influxes of migrants themselves led to an abandonment of catholic values. Thus, religion did not stimulate the rise of populist parties but in contrast, the catholic values held by the majority of Maltese continue to play a strong role in the daily life. This also prevented significant cultural changes arising from an increased ethnic diversity due to immigration, wherefore the little bit that defined a Maltese identity was not destroyed. Thus, the second D of destruction is not fulfilled here either as cultural changes were not significant enough to change the Maltese nationality. 


\subsubsection{Dispersion of the Maltese territory}

Technically, as Malta is a relatively small country, its size could contribute to good political relations between the electorate and the voter as politicians would be 'nearer' to the public e.g. because they live in the same area etc. However, this is not the case in Malta, even if the country is small, its territory is dispersed over three islands. Thus, it is more difficult for politicians to form close bonds with their voters if they are separated by sea as they don't necessarily tour the country except during election time. Thus, another argument that could be put forward in preventing populism to spread is the dispersion of the Maltese population. However, thanks to modern technologies, the argument is contested as the use of social media, television and radio even encourages long-distance connection and thus does not prevent the spread of (far-right) ideas but in contrast, may even stimulate a faster dispersion (Falzon \& Micallef, 2008, p. 401). In the internet, individuals may express their opinions freely as part of their freedom of speech and not always are radical and discriminatory discourses detected and censored (Falzon \& Micallef, 2008, p. 401). This can be seen in the case of the Vivamalta website, which essentially constituted an online forum for far-right advocates to exchange opinions anonymously. Maltese far-right ideologists furthermore can connect with similar movements worldwide.

Falzon and Micallef have concluded "Maltese far right ideas and discourses are anything but 'local'", despite being rooted in Malta due to church criticism, immigration and anti-establishment sentiments (Falzon \& Micallef, 2008, p. 401). The dispersion of the Maltese nation is thus not preventing the spread of populist sentiments but at the same time, the increasing use of the internet does not stimulate it either. The Maltese thus don't necessarily have close personal bonds with their politicians, but that does not mean that they would de-align easily as party affiliation is still strong, which is furthermore reflected in the high trust in government, as outline above. Hence, the fourth $D$ is not fulfilled either. Nevertheless, even if the Maltese are not (yet) de-aligning from the mainstream parties, also because they have been established for so long, only $36 \%$ of Maltese respondents said in the Eurobarometer survey that they trust their political parties, despite rising by $10 \%$ and thus slightly improving (Eurobarometer, 2018). This is most likely due to corruption problems, which are further worsening due to scandals such as Panama papers or the Golden visa scheme, where Maltese citizenship can be bought by any foreigner (Muscat, 2019).

\subsubsection{Relations with the EU}

Euroscepticism is often considered another promoting factor in the rise of populist sentiments (Poli, 2016; Eatwell \& Goodwin, 2018). Poli (2016) argues that EU resentment is a big part of why populist parties were successful especially in Italy, Greece, the UK and Poland (p. 46). Until shortly before its accession in 2004, the Maltese held strong Eurosceptic sentiments. However, since the beginning of their EU membership, these sentiments have shifted and made place for a general feeling of proEuropeanism: $56 \%$ of Maltese "tend to trust" the EU, which is $12 \%$ higher than European average (Eurobarometer, 2018, p. 6).

In order to explain this shift, it is necessary to look at the accession of Malta and its relations with the EU as the path to accession and euro enthusiasm was a long one. Ever since the beginning of the 1990s, the Nationalist Party strongly promoted the accession to the European community (Harwood, 2014 , p. 195). This euro enthusiasm soon became the main source of friction between the two main parties, the Nationalists and the Labor Party, as Labor envisioned a Switzerland-alike and more Eurosceptic relationship with the EU (Harwood, 2014, p. 196). When Labor came back to power between

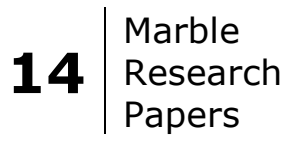


1996 and 1998, the membership application was frozen. However, with the Nationalists back in power from 1998 on, the application was reopened but the EU demanded new standards that Malta firstly had to fulfill before being able to access the community (Harwood, 2014, p. 196). However, it took until 2004 until Malta become part of the EU. Labor, by the time that Malta had joined the EU, had changed its agenda and started to encourage EU relations in order to respect the will of the people, expressed in an EU-membership referendum (Harwood, 2014, p. 196). Afterwards, there was barely any difference between both the Nationalists and Labor left in their policies. Malta then took on its responsibilities in the European sphere by actively contributing to foreign policies and even missions and was eventually seen as a very cooperative partner. In doing so, even as the smallest state, Malta established itself well in the European sphere. Despite having transparency, resource, administration and corruption problems, Malta enjoys one of the best records for transposition and implementation of EU policies and has been issued only few complaints (Harwood, 2014, p. 226). However, this was thanks to the centralization of its politics, through which it can act unanimously much easier and control its external message (Harwood, 2014, p. 227).

Malta was able to enjoy most of the benefits of EU membership during the first 15 years of its accession and still could maintain national sovereignty and voice its opinion despite being the smallest Member State. Due to that, the Maltese have become increasingly enthusiastic towards the EU and have thus no reason to vote for populist parties that simultaneously oppose the EU and all it stands for, leading back to the first D, namely distrust in politicians. Even if populist parties like Imperium Europe slowly gain votes, they cannot significantly challenge elections. There is thus no distrust in politicians, not to local politicians and not even towards the EU and its representatives, despite the anger the Maltese held towards them because of the repercussions of the migration crisis.

\subsubsection{Role of the political system}

The last of the four D's offered by Eatwell and Goodwin concerns the bonds between the electorate and the politicians themselves and thus somewhat links back to the first $D$ concerning trust in the political system. Thus, is it crucial to examine the political state of the country, especially with Malta being an exception compared to most other European countries. The Maltese political system is characterized by a bipartisan formulation with the two main parties being the center left Labor Party and the Christian democrat Nationalist Party (Falzon \& Micallef, 2008, p. 393). Additionally, despite not having a compulsory voting, Malta has one of the highest electoral turnouts of all liberal democracies, with more than $93 \%$ turning up on polling day (Cini, 2002, p. 11). However, as their pure two-party system is of a very rigid nature with more than $95 \%$ of the votes in total going to the two main parties, there is only little space for new and smaller parties to step up in the system (Cini, 2002, p. 9). Due to a highly polarized electorate, the two main parties thus usually have an almost equal prospect of becoming the incumbent power. Cini (2002) argues that because the system is rigid, the main parties focus on floating voters and thus adjust their programs to the center of the political spectrum to attract these, despite having a very similar agenda (p. 8). Thus, they try to attract the same unsatisfied voters that populist parties in a way also try to attract. However, the fact that the political system in Malta is so centralized and leaves almost no space for other parties, is only partly explained by the use of the Single Transferable Vote (STV) as a voting method. This method lessens the likelihood of two-party systems by proportionally representing the different districts and allocating votes per candidate preferentially, instead of per party is supposed to enhance representation (Cini, 2002, p. 15; Bowler \& Grofman, 2000, 
p. 179). Because it does not focus on the party but on the individual candidates, it does not necessarily undermine the possibility for smaller parties to succeed as long as their candidates have a large enough following to pass the quota for a seat.

Moreover, strong party affiliation is explained by the fact that it constitutes a form of expressing identity. Because there is no such thing as a national identity, and church affiliation does not fill the gap internally because almost all Maltese belong to the same church, party affiliation can be a strong expression to differentiate oneself from other Maltese (Baldacchino, 2009, p. 154). Conclusively, the political system thus does not exclude smaller political parties per se, but for new far-right parties to take part in the competition for parliamentary seats, they need bigger responsiveness in the Maltese population as a bigger following means more votes for their respective candidate. This is however not the case in Malta as populist tendencies are not shared by many. Additionally, this strong party affiliation emphasizes the close bonds between electorate and party. There is thus no sign of dealignment with the incumbent and opposing politicians which thus did not pose a reason for populism to rise. Hence, the fourth $D$ is not fulfilled in Malta either.

\section{Conclusion}

This research has shown the dimensions of Maltese populism. It can be confirmed that Malta does not currently have a problem with populism, however, it is unsure as to what the future holds as populism is nevertheless existent in the Maltese society. Populism was not able to spread because there is only little responsiveness to more radical and far-right rhetoric which is due to many different factors. The two examined crises were disturbing to the Maltese society and thus it would not have been surprising to see a rising sympathy for populism result from them, as was analyzed earlier. However, the strong church affiliation and the importance of catholic values supported the anti-populism stance. The political system additionally does not undermine the rise of populist parties due to its institutional framework per se, but because of the high polarization of the country and strong links with the main parties, populist parties would need a huge following to overtake the main parties. Furthermore, the good economic state of the country gives its people almost no reasons to vote for radical and anti-everything parties. The good EUMalta relationship was another factor in facing populist parties, as the majority of the Maltese have become very pro-European over time whereas in contrast populist parties usually contest the importance of such supranational organizations. However, the ongoing socio-cultural cleavages that exist in the country in terms of language, identity and politics might become problematic eventually. Moreover, the good economic state of the country must be upheld, and existing social problems need to be tackled in order to prevent populism from gaining ground in the next decades.

The four D's offered by Eatwell and Goodwin have explained the rise of populist parties in many other European countries, but by barely being existent in Malta, it can be concluded that Malta is an exception to the populist trend. Nevertheless, it is somewhat surprising how the country despite having strong links with its (partly populist and euroscpetic) neighbor or former colonial mother countries, managed to avoid a general spread of the ideology and thus prove to be an exceptional case in the populist surge across Europe. This study was supposed to fill the gap concerning literature about the (non)-existence of populism in Malta and trusts to have contributed to it by proposing an analysis based on different perspectives. However, more research needs to be done on Malta in general but especially on its unique role in the European system which is thanks to an exceptional internal structure. This research is thus limited by the relatively small amount of literature concerning not only populism in 
Malta but also internal insights into economy, culture and politics. Additionally, space limitations did not allow an in-depth analysis of all the factors that should be taken into account. Nevertheless, it is hoped that the analysis was able to provide new insights into the populist phenomenon and the exceptional case of Malta, which is often neglected in political discussions. However, the argument of this research might change in the future if the Maltese take their immunity for granted as the 2019 European Parliament election confirmed the rise of populism, even in Malta, despite still being marginal. 